\title{
PHOTOGRAMMETRY FOR QUICK SURVEY IN EMERGENCY CONDITIONS: THE CASE OF VILLA GALVAGNINA
}

\author{
V.M. Nannei ${ }^{1}$, F. Fassi ${ }^{2}$, G. Mirabella Roberti ${ }^{3}$ \\ ${ }^{1}$ Graduate School in Architectural and Landscape Heritage, Politecnico di Milano, Italy, virna.nannei@mail.polimi.it \\ ${ }^{2}$ Department of Architecture, Built Environment and Construction Engineering, Politecnico di Milano, francesco.fassi@polimi.it \\ ${ }^{3}$ Department of Engineering and Applied Sciences, Università degli Studi di Bergamo, giulio.mirabella@unibg.it
}

\author{
Commission II, WG II/8
}

KEY WORDS: photogrammetry, 3D reconstruction, emergency survey, cultural heritage, conservation.

\begin{abstract}
:
Photogrammetry is a survey method that provides good quality results also by using basic photographic equipment and user-friendly, low-cost software. The advantages of the image-based modelling techniques compared with the traditional topographic tools are very significant in emergencies, when the time for the survey is limited and many buildings are involved, as usually happens in case of relevant seismic events. The goal of this study is to verify the quality of the models obtained from quick digital images acquisition, carried out under non-optimal lighting condition and no accessibility of the building. As case of study was chosen the main front of Villa Galvagnina in Moglia, a Renaissance hunting palace badly damaged by the earthquake of May 20, 2012. The modelling was performed using two different software, Agisoft Metashape and 3DFlow Zephyr. This paper presents a comparison between the results obtained using different datasets; the workflow, the difficulties encountered during the survey and the data processing methods are fully described and discussed.
\end{abstract}

\section{INTRODUCTION}

Modern digital photogrammetry is an architectural survey method that allows obtaining good quality results even without professional instruments, thanks to the diffusion of "easy to use" and efficient photogrammetric software. In comparison with the traditional topographic tools, the advantages that photogrammetric methods offer in emergency situations are particularly considerable, both when the time for the survey is limited and when the large number of involved buildings does not allow the detailed planning of large surveying campaigns, as it usually happens in case of relevant seismic events.

As a matter of fact, modern digital photogrammetry needs a much lower budget, both in terms of equipment cost, and in term of requested time, respect to the use of laser-scanner. Nevertheless, the construction of a tri-dimensional model allows extracting an orthographic projection that, unlike a plane picture produced by a simple photo straightening, is geometrically correct in the three dimensions.

This allows extracting important information, useful for example for a structural modelling of the building. Moreover, in the tri-dimensional model it is possible drop out disturbing details, such as scaffoldings, allowing a complete recording of the conservation conditions of the surfaces. Last, the production of a tri-dimensional model allows eventually later the transposition of information in a BIM model, a tool more and more appreciated also in the management of cultural heritage.

The main goals of this study are to develop a suitable pipeline of quick survey procedure for cultural heritage using photogrammetric techniques, useful for the strengthening and conservation projects, and to verify the quality of the models that can be obtained also from sets of photographic shots acquired under non-optimal lighting conditions and accessibility of the building. Moreover, the short-time acquisition has been considered. Two different photogrammetric software have been used during this study: Agisoft Metashape and 3Dflow Zephyr. Zephyr was used to align photos taken with different lenses at once and compare the results obtained, while Metashape was used to test a different method to extract orthophotos.

\subsection{The case study}

The main front of Villa Galvagnina in Moglia, in the province of Mantua has been chosen as a case study: it is a Renaissance hunting palace, badly damaged as a result of the earthquake of May 20, 2012, an earthquake of magnitude $\mathrm{ML}=5.9$ that hit a vast area of the Po Valley, between Lombardia, Veneto and Emilia, with the epicentre near Finale Emilia.

The affected area is characterized by a low historical seismicity. No recent earthquakes of sixth grade of the Mercalli Scale or greater are known, given that an intensity of sixth grade of the Mercalli Scale corresponding to a quake that causes some little damage in the buildings and makes the windows shatter. The main exceptions are the earthquake that occurred in Ferrara on November 17 of the 1570, classified between sixth and eighth grade in the Mercalli Scale, corresponding to the collapse of some buildings (Galli et al., 2012), and the earthquake that occurred on April 6 of the 1639, that had the epicentre in Finale Emilia with an intensity between the sixth and eighth grade in the Mercalli Scale (Arcoraci et al., 2012).

According to the damage survey conducted by the National Institute of Geophysics and Volcanology (Arcoraci et al., 2012), the historical buildings made prior to the Second World War in the area shaken by the earthquake revealed a constant absence of effective connections among the structural components, like tie rods. Those devices are commonly used in other areas of the Italian territory with higher historical seismicity.

The building that is the object of this study makes no exception. It has a structure characterized by masonry walls and wooden floors and roof, an almost square plant with a side approximately of $22 \mathrm{~m}$ and a height of $10 \mathrm{~m}$ for the eaves. The small thickness of the masonry walls and the lack of connections between them, associated with the complete abandonment of the villa since the 1960 s, have led to a progressive deterioration of the ancient building. For this reason, several attempts have been made to preserve the 
structure through the installation of temporary provisional supports. This shoring could have prevented the complete collapse of the villa, while not avoiding the aggravation of an already worrying crack pattern and the loss of considerable portions of the decorative apparatus.

The damages caused by the earthquake made an emergency consolidation work necessary, so that the Municipality of Mantua, the owner of the hunting palace, has arranged for the installation of an external reinforcement ring, consisting of a steel trusses and ties structure. Only after this provisional structure was set, the Municipality proceeded to commission a laser scanner survey, which has been used to validate the results obtained during this study.

The presence of the articulated system of reinforcement and of a wire-net fencing at about $17 \mathrm{~m}$ from the front are the main elements of disturbance in the process of acquisition of photographic images, whose quality is directly proportional to the quality of the result of modelling procedure. At the same time, they contributed to define a non-ideal situation that realistically reflects a situation typical of survey in emergency conditions. In particular, the presence of the horizontal steel pipes and ties has determined the generating of missing areas in the model, since it was not possible to carry out photographic shooting at different heights to allow the reconstruction of the portions of the façade covered by these elements.

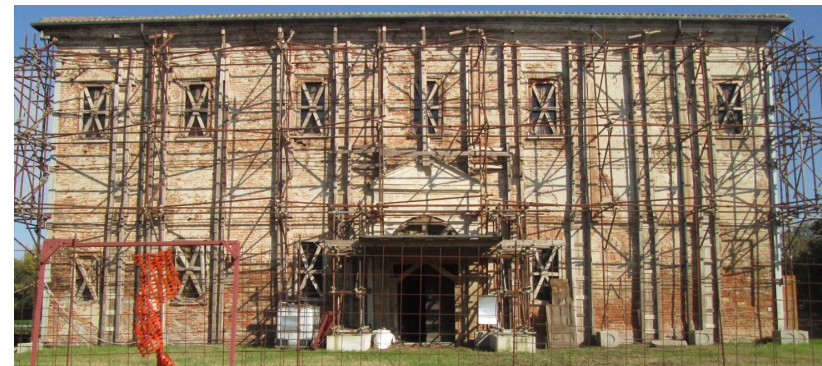

Figure 1: The main front of Villa Galvagnina in Moglia

\subsection{Photogrammetric survey for cultural heritage}

In the nineteenth century, the invention of the daguerreotype process opened the way to the development of tools able to provide an automatic reproduction of reality. In fact, the images obtained were not affected by the interpretation of the artist such as sketches and paintings that had been the only available techniques for historical sites surveys until then (Fassi and Campanella, 2017)

In the same period, the early theories for the restoration of the ancient buildings were developed. Even then, John Ruskin understood the importance of the new techniques in order to record the "true" condition of a historical site, given the growing attention paid to the physical characteristics of the monuments. Indeed, the idea of "authenticity" in a heritage resource was emerging and so starting from the invention of the daguerreotype, instruments for automatic images acquisition have played an increasingly important role in the study and preservation of cultural heritage.

In the second half of the nineteenth century, the advent of photography allows the development of studies on the extraction of measurements from images, as well as qualitative data

In the first half of the twentieth century, photogrammetry had become an established survey technique. In the $60 \mathrm{~s}$, a new impetus came from the diffusion of powerful computers allowing to formalize the equations in order to obtain the orthogonal projections of an object starting from a stereoscopic pair of images.

The most recent innovation in the field of photogrammetry was determined in the $1990 \mathrm{~s}$ by the development of digital photography; now, three-dimensional modelling of archaeological sites and historical building can be produced using specific software (Fassi and Campanella, 2017).

The digital models obtained using image-based techniques are characterized by a low error and therefore a high geometrical correspondence to reality. However, it should be underlined that every model is still an interpretation of the reality and it depends both on the accuracy of the instruments and on the choices made during the survey process (Fallavolita et al., 2015): this is a fundamental assumption to be remembered when approaching survey of cultural heritage. 3D digital models could have different aims, including structural analysis, the implementation of interactive models for educational purposes and the collection of several data as support for the management of cultural heritage (Carboni et al., 2016).

In this regard, the development of BIM models, suited to collect all information relevant to study and protect an ancient building, such as the characteristic of the materials or previous restoration works, is the last frontier of image-based modelling. On this subject, a very relevant example is the survey of the Milan Cathedral carried out by Fassi et al. (Fassi et al., 2018).

Moreover, the image-based modelling techniques can also be used to draw up an accurate mapping of materials and decay phenomena, which is essential for conservation projects.

\subsection{The workflow}

The workflow adopted for the quick survey of the Villa Galvagnina main front using photogrammetric techniques is described hereafter, from the acquisition and the postprocessing of the data, up to the restitution of the front through orthophotos, a key product in the context of a conservation project. Actually, mapping the materials that constitute the ancient building, the possible deteriorations and the cracking pattern, as well as making an accurate stratigraphic analysis, are procedures that require the usage of qualitatively detailed and quantitatively correct orthophotos in a scale not less than 1 to 50 .

The workflow consisted of the following steps:

1. Data acquisition: two different acquisition campaign were performed, under different capturing conditions and using three different cameras, one of them whit two different lenses. Two sets of photographs have been selected for batch processing.

2. Image-based modelling process: a complete automatic pure photogrammetric process of the images "as is" with the aim of obtaining a dense point cloud as result. The datasets were processed using two different software packages, Agisoft Metashape and 3D Flow Zephyr. Every dataset was processed both using constraints and not using them. 25 points collected from the laserscanning point cloud provided by the Municipality of Mantua were used as constraints.

3. Comparison between the cameras orientation processes, with and without constraints, using the control points errors provided by Metashape or the Zephyr dedicated tool.

5. Orthophoto export: a complete automatic process of the point cloud to export an orthophoto of the main front of the villa. 


\subsection{The comparison criteria}

In order to evaluate the accuracy of each photogrammetric point cloud, a laser scanning survey has been taken as the ground through reference model, given that the laser scanning techniques for surveying are well discussed in scientific literature.

To perform the comparison between all the sparse point clouds, in order to evaluate the accuracy of the camera's alignment, the dedicated tool of Zephyr have been used. "Point cloud comparison" function allows a fine comparison between two selected point clouds and the plotting of a chart that graphically shows the residuals and returns the mean error and variance.

The first step of the comparison process computes the closest point of the model for every point of the target. If a distance between a couple of points is greater than the maximum distance value permitted, that distance won't be considered into the computation. Then, the histogram is built by considering the closest point A for each point B. All the spatial distances are from $\mathrm{A}$ to $\mathrm{B}$ are used to build the histogram and colour the point cloud accordingly (3DFlow, 2018).

Lastly, the coloured point clouds and the mean and maximum errors were compared.

\section{RELATED WORKS}

Due to the potential of the image-based modelling application in the field of cultural heritage, the development of photogrammetric techniques and especially structure from motion techniques are being investigated by several research groups. Among them, it is worth mentioning the study carried out by J. Valença to establish guidelines to best-practice procedures and to validate the results obtained by application of close-range photogrammetry to build $3 \mathrm{D}$ geometric models and for evaluation of displacements (Valença, 2014).

Useful suggestion for good working practices can be found in the research conducted by Carboni et al., that develops a pipeline for imaged-based modelling process, in order to assure data provenance and enable the validation of the operations from an analytic and production perspective (Carboni et al., 2016).

Furthermore, explanation on how to run a proper survey using structure from motion techniques may be found in the Agisoft Metashape (Agisoft, 2019) and 3D Flow Zephyr (3DFlow, 2018) user's guides and in the handbook Photogrammetric Applications for Cultural Heritage. Guidance for Good Practice (Historic England, 2017).

The comparison between a laser scanner point cloud and a photogrammetric point cloud in order to assess the accuracy of the structure from motion techniques is an extensively analysed evaluation method. On this issue, the work of Fassi et al. is been a handy reference. The authors compared the laser scanner and photogrammetric point clouds, testing three case studies: an archaeological site, the main front of a church and a dome (Fassi et al., 2013).

The advantages that photogrammetric methods offer in comparison with the traditional topographic tools, are fully discussed in Perfetti et al. (Perfetti et al., 2019). The authors investigated the possibility to create a single high-resolution $(<5 \mathrm{~mm})$ orthophoto to represent very complex and extensive facades.

The landscape of commercial software for the image-based modelling is various and still evolving. As regards to the comparison between different software packages, the studies conducted by Nikolov and Madsen (Nikolov and Madsen,
2016), Alidoost and Arefi (Alidoost and Arefi, 2017) and Gaglioloa et al., (Gaglioloa et al., 2018) can be mentioned. The paper written by Nikolov and Madsen took into account both PhotoScan, the previous photogrammetric software by Agisoft, and 3DFlow Zephyr.

Finally, the work proposed by Di Tondo and Fabrizi is an interesting example, which shows that sometimes it is necessary to use image datasets gained not under the best capturing conditions. The authors developed a 3D digital model of the Abu Simbel temples beginning from the original data of the photogrammetrical survey carried out in the 1950s, before they got moved. The model was compared with the one obtained from recent images. The impossibility to carry out a direct survey, because of the political situation, led to use touristic shots to create the structure from motion model (Di Tondo e Fabrizi, 2013).

\section{DATA ACQUISITION AND PROCESSING}

\subsection{The acquisition campaign}

The on-site image acquisition was conducted using three different cameras, under different capturing conditions, to perform a kind of software stress test. In fact, the need to use non-professional tools can occur in emergency situations and in extreme cases, images not acquired during specifically planned surveys must be used, such as the modelling of the Abu Simbel temples (Di Tondo e Fabrizi, 2013).

The following cameras have been used:

1. Nikon D3200: the camera has a $23.2 \mathrm{~mm} \times 15.4 \mathrm{~mm}$ sensor with a maximum resolution of 6016 pixels $x$ 4000 pixels, equipped with an $18 \mathrm{~mm}$ focal length lens.

2. Sony IMX234 Exmor RS: the main camera of the LG H850 mobile phone has a $5.95 \mathrm{~mm} \times 3.35 \mathrm{~mm}$ sensor $(1 / 2,6 ")$ and a maximum resolution of 5312 pixels $x$ 2988 pixels, equipped with a $4.42 \mathrm{~mm}(29 \mathrm{~mm}$ equivalent) focal length lens.

3. Canon Eos 5D mark II: the camera has a full frame (36 $\mathrm{mm} \times 24 \mathrm{~mm}$ ) CMOS sensor with a maximum resolution of 5.616 pixels $\times 3.744$ pixels, equipped with two different lenses, one with a $24 \mathrm{~mm}$ focal length and one with a $70 / 200 \mathrm{~mm}$ focal length. The camera was set up on a tripod.

The acquisition of the data was conducted during two different days, at different times, so some photographs taken with the Canon camera had benefitted from diffused lighting, but most of the photographs are affected by strong light and shade effects, due to the direct irradiation of the surfaces and the projection of the reinforcement ring' shadows.

As already mentioned, it was not possible to take photographs at different heights levels, as suggested to reduce the interference of the horizontal still pipes and ties.

The initial purpose was to perform an as quick as possible data acquisition campaign to simulate the conditions of an emergency survey, and to compare the results obtained with a reflex camera (Nikon D3200) with those obtained with a mobile phone camera (the main LG G5 camera).

In order to overcome the difficulty of taking photographs at different heights, an image acquisition grid was adopted at increasing distance from the building. Although this is not an optimal procedure, which implies an increased GSD, it allows to vary the angle of incidence of the photo shots, thus trying to capture all the parts of the masonry covered by the reinforcement. 
376 photos were taken with the Nikon camera and 798 photos with the mobile phone. These photographs were selected using the image quality index calculated by Zephyr, so 234 photos taken with the Nikon camera at a distance between 2.8 and 13.2 metres from the building (maximum GSD $=2.8 \mathrm{~mm}$ ) and 323 with the LG camera at a distance between 0.7 and 7.2 metres from the building (maximum GSD $=1.8 \mathrm{~mm}$ ) were used.

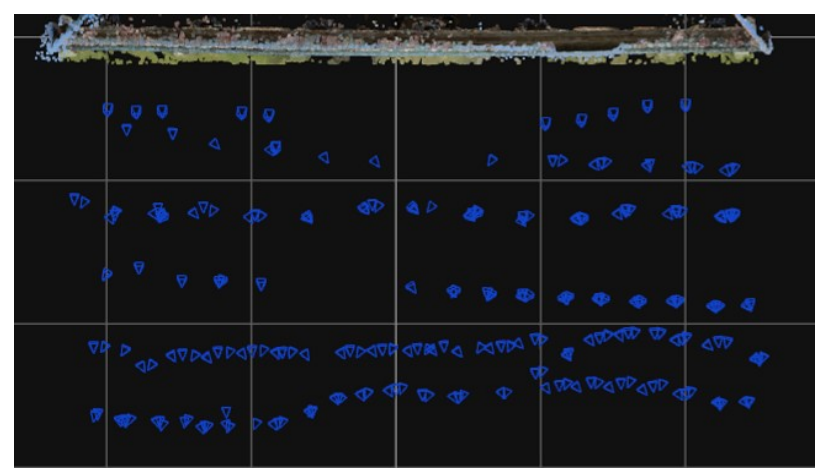

Figure 2: Nikon photos acquisition path.

To improve the quality of the model in the upper part of the building, the images acquired with the Nikon camera were subsequently integrated using the Canon camera, that had a telephoto lens, using a telescopic ladder to take shots at a height of about three meters above the ground.

181 photos were taken with the $24 \mathrm{~mm}$ focal length lens of the Canon camera at a distance between 5.5 and 11.8 metres from the building (maximum GSD $=4.1 \mathrm{~mm}$ ) and 64 with the telephoto lens (131 mm focal length), at a distance between 21.0 and 22.4 metres from the building (maximum GSD $=1.5$ $\mathrm{mm})$.

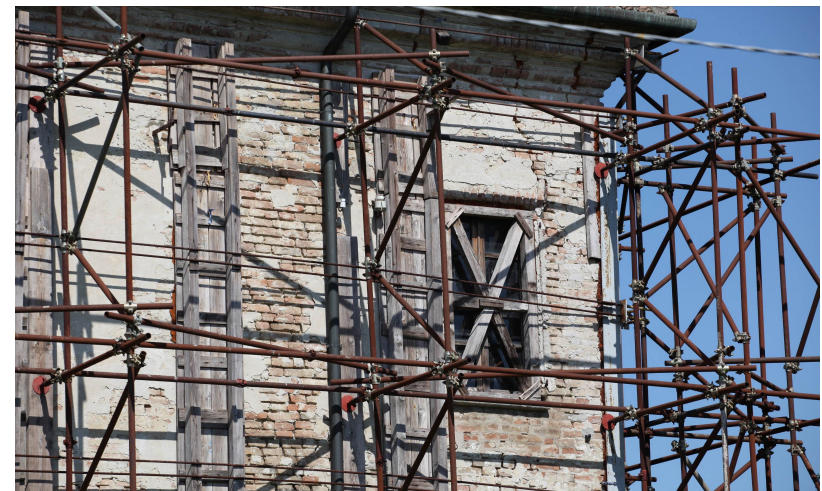

Figure 3: Building detail taken with the Canon telephoto lens. This lens allowed obtaining less distorted images of the upper part of the building.

Although the use of different lens processing a photogrammetric model is not the best course of action, current software can process images taken with more than one lens during the camera's alignment step. However, a great overlapping (more than $85 \%$ ) must be assured.

The acquisition for all the cameras followed the scheme of a photo with optical axis perpendicular to the façade and two from the same position tilted of circa $10^{\circ}$ left and right (Nocerino et al., 2014). This schema will theoretically assure a good rigidity in the photogrammetric block and can be also useful to capture façade areas behind scaffold pipes.

The laser scans provided by the Municipality of Mantua were performed using an HDS 7000 Leica Geosystems laser.

\subsection{The data processing}

For data processing, three different computers were used, in order to save computational time, but it can be said that a couple of weeks are needed to process each data set with great accuracy up to get a detailed orthophoto.

All the image sets were processed with 3DFlow Zephyr, to compare the first step of the process, in which the software extracts the camera external parameters (positions and orientations) and their internal parameters (i.e. the focal length and other camera properties) and build a sparse point cloud model. Only the Nikon images were processed with Metashape, in order to compare two methods of orthophoto extraction. Both software computed the self-calibration.

Both software allows to choose the level of accuracy of data processing, but it should be remembered that setting the parameters to the highest definition leads to a considerable increase in the computation time. Furthermore, it does not guarantee a better outcome, especially when the quality of the images is not very good.

Using Zephyr, each data set was analysed both using 25 control points of the laser scanning cloud as constraints, and without any constraints. A high key point density and an accurate matching were set for the cameras orientation. Then, a dense point cloud was produced from the first dataset (Nikon and Canon cameras at once, 25 constraints), using a high resolution and a low noise filtering level. The final cloud counts circa 20 million of points.

Finally, a coloured mesh was extracted, using the photoconsistency based optimization. The dense cloud was cleaned before extracting the mesh.

The result shows that, although high resolution images allow to obtain orthophoto detailed enough to draw up the materials and decay mapping (Figure 7), it would have been necessary using not more than two lenses and better lightning conditions for a more accurate restitution.

In Agisoft Metashape, only the Nikon dataset was analysed. The whole image block (234 cameras) was divided into two separated chunks, one with closest cameras ( 85 cameras) to the facades and one with the most distance (58 cameras). Some other shot was not elaborated because unnecessary. This was useful to separate photos with different focus and with consequent different internal parameters.

The two blocks were aligned separately. The orientation for both gave a mean reprojection error of 0,1 pixel and a final error on GCP (the same used inside Zephyr software) of $4 \mathrm{~mm}$ after an aggressive selection and elimination of tie point with high reprojection error and with high reconstruction uncertainty and successive phase of optimization. The two blocks where aligned together with a point matching process and then merged with a total final error in the two-chunk registration of $8 \mathrm{~mm}$ on the common targets position.

In order to eliminate some redundant images in the dense point cloud elaboration a calculation of the overlap is computed disabling exceeding photo but maintaining a high coverage value. Point cloud was created using a downscaling of the image of $1 / 4$ of the initial areal resolution (high value). The point cloud results very noisy and full of outliers for the presence of the scaffolds: a manual cleaning was mandatory to get a usable mesh surface. The final cloud counts circa 34 million of points. The mesh was created using the maximum possible resolution and the final mesh had circa 74 million of triangles. The orthophoto generation was computed automatically using all the images with a final resolution of $2 \mathrm{~mm} / \mathrm{px}$. The presence of the scaffold, as expected, made the use of the original orthoimage not usable for wrong reprojections, pipes shadows and the pipis 
covering the wall. For every scaffold pipes a manual polygonal selection was done and the correct photo was chosen. In the image below the difference between the original orthoimage and the final after manual intervention. The shadows can be eliminated in a subsequent moment inside a software for image elaboration.

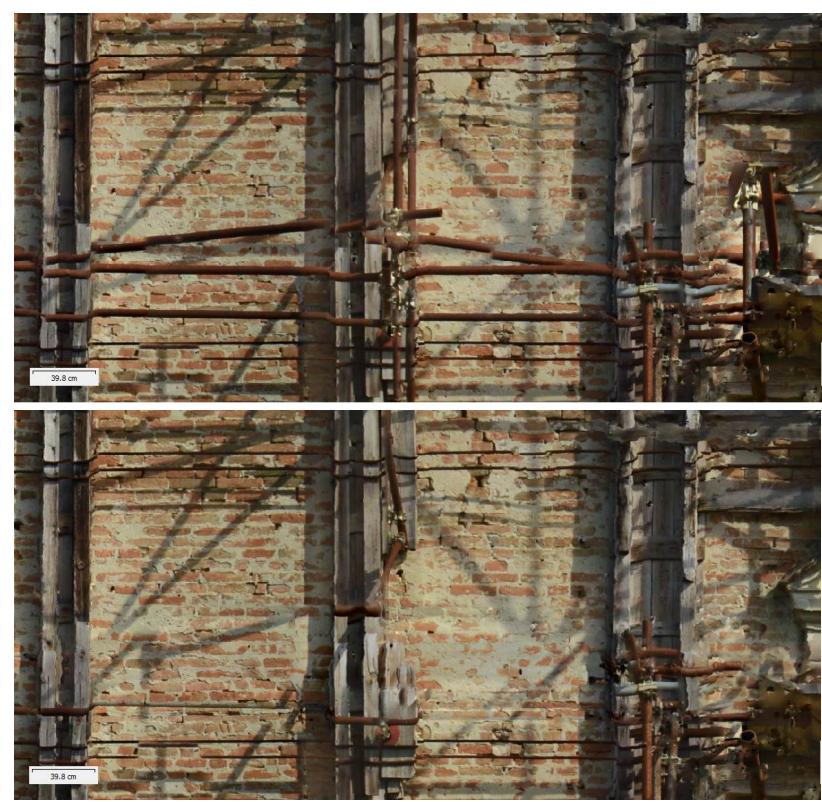

Figure 4: Before and after the manual photo selection for orthophoto creation in Metashape.

\subsection{Comparison of the different datasets results}

A comparison was done between the laser scanning point cloud and the tie points (sparse point clouds) processed with Zephyr from Dataset 1 (Nikon camera integrated with the Canon camera shots) and Dataset 2 (LG camera), with and without GCP constraints.

In order to compare the photogrammetric and the laser scanner point clouds using the Zephyr specific tool, it was necessary to import them in the same model space. The laser scanner point cloud provided by the Municipality of Mantua was considered the local reference system. The point clouds processed without constraints were registered in the reference system using six of the GCP identified on the clouds after the cameras orientation.

The analysis returns the histogram of the deviation between each laser scanner point and the closest photogrammetric points (residual) and the average and the maximum errors. The comparison shows that, quick and not planned data acquisition campaign can provide acceptable photogrammetric models, even if those models haven't the target accuracy (Table 1). In fact, all the point clouds have an average error between 0,0188 $\mathrm{m}$ and $0,0235 \mathrm{~m}$, greater than the target error (less than $0,01 \mathrm{~m}$ ). The maximum residuals show that using control points is a key of the camera orientation step.

\begin{tabular}{|l|c|c|}
\hline Dataset & Average residual [m] & $\begin{array}{c}\text { Maximum residual } \\
{[\mathrm{m}]}\end{array}$ \\
\hline 1 (With const.) & 0,0235 & 0,0708 \\
1 (Without const.) & 0,0188 & 0,1023 \\
2 (With const.) & 0,0193 & 0,1475 \\
2 (Without const.) & 0,0205 & 0,1499 \\
\hline
\end{tabular}

Table 1: Average and maximum residual obtained comparing the sparse point clouds processed with Zephyr with and without constraints to the laser scanning point cloud.
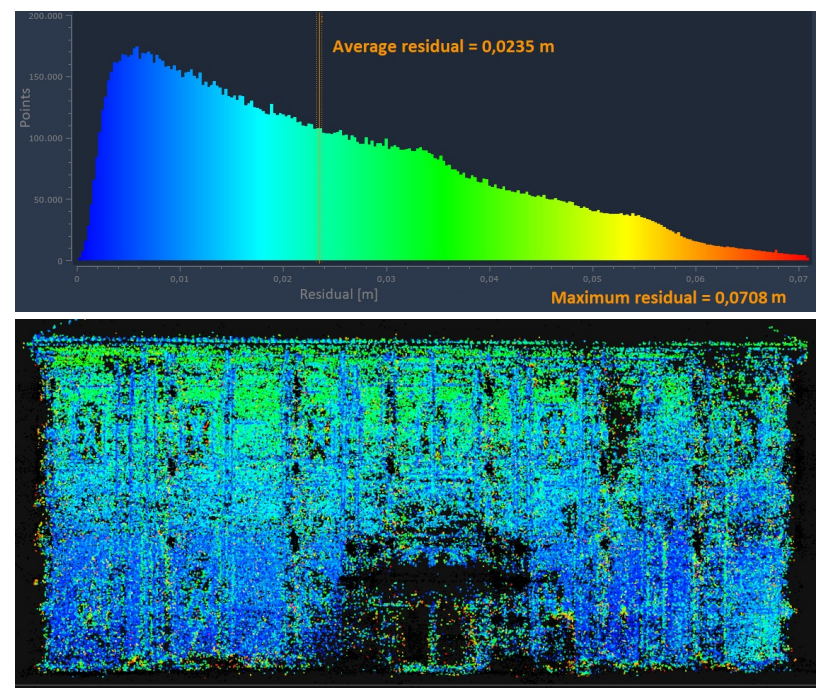

Figure 5: Comparison between the laser scanner point cloud and Dataset 1 (Nikon and Canon cameras shots) cloud processed using 25 constraints: histogram of the residuals and coloured point cloud. Blue points show below average residuals, while the green show above-average residuals.
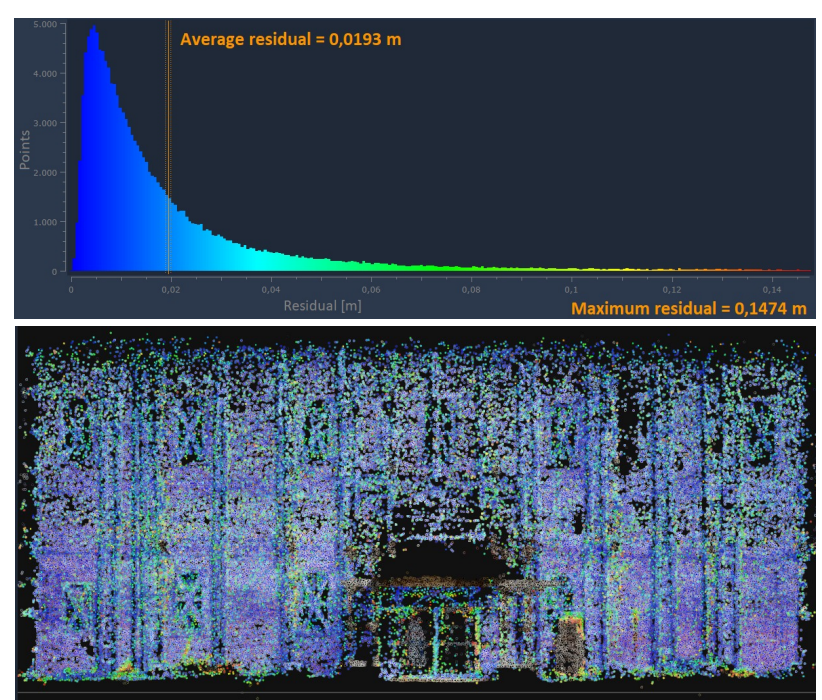

Figure 6: Comparison between the laser scanner point cloud and

Dataset 2 (LG camera shots) cloud processed using 25

constraints: histogram of the residuals and coloured point cloud.

Blue points show below average residuals, while the green show above-average residuals.

The first dataset point cloud coloured according the histogram of the residuals (Figure 5) highlights that the upper part of the model has a worst accuracy, probably due to the using of the telephoto lens to take image of this part, while the second dataset has a homogenous distribution of the greatest errors (Figure 6), due to the noise of the sparse cloud (low accuracy in the reprojection error).

As proved by the histogram of the residuals, the use of different lenses led to a sharp increase in the variance of the error, while the dataset acquired using the mobile phone is free from this defect. 



Figure 7: On the top the orthophoto of the main front of Villa Galvagnina extracted from Zephyr (a). On the centre the original orthophoto created with Metashape (b) and on the bottom the same after the manual individuation of correct photo projection (c). 


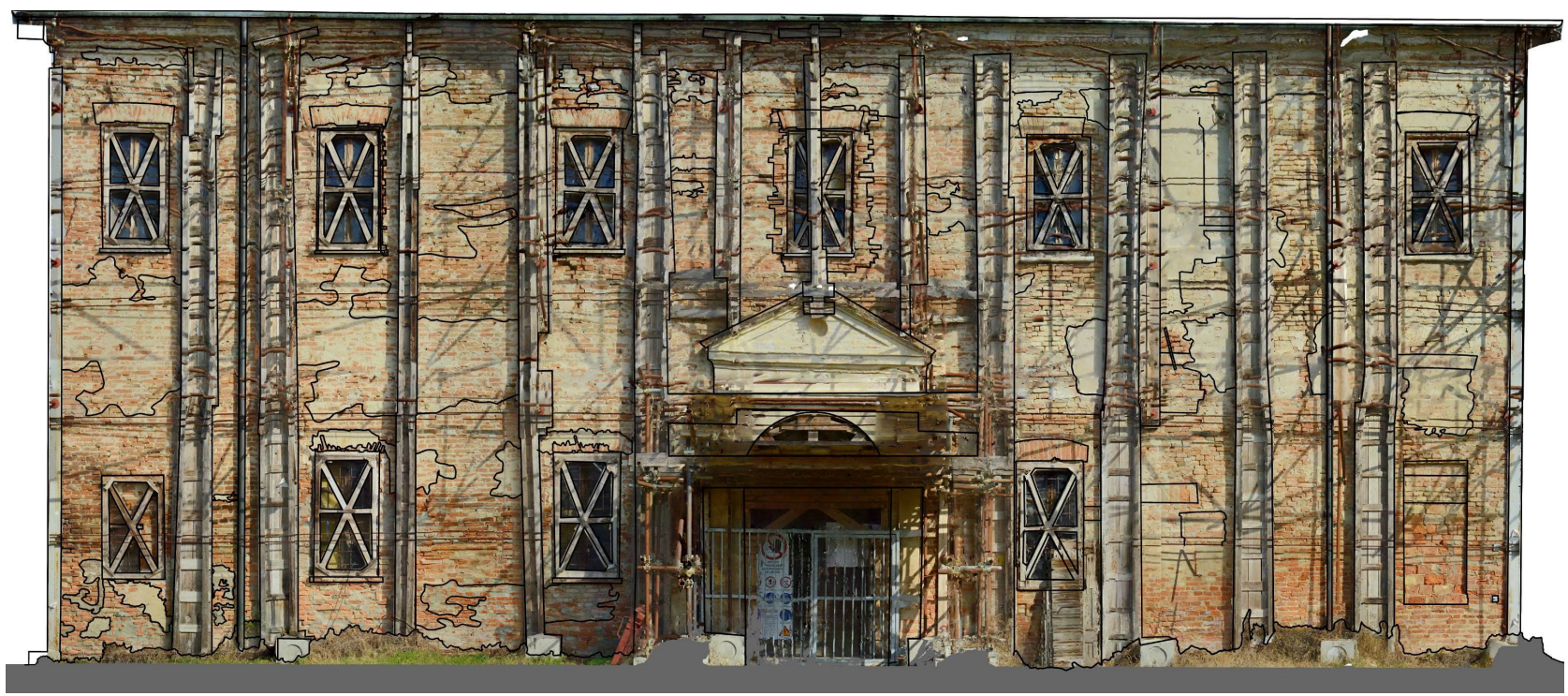

Figure 8: Stratigraphic analysis, first draft. The reinforcement system prevents the correct interpretation of the stratigraphic units.

\section{CONCLUSIONS}

This study shows how photogrammetric techniques allow to obtain 3D models that have a sufficient accuracy for the materials mapping in a scale 1:50 even if the object position and condition was not ideal and the photogrammetric acquisition was not performed as suggested by a photogrammetric point of view (Fassi et al., 2015). However, the results are positive by the good acquisition geometry. In particular, the image overlapping, the lighting conditions and the degree of perspective distortion of the shots and the number of the images have proved to be key issues in order to obtain a high definition mesh.

The main advantage of photogrammetry compared to laser scanning techniques is its lower cost and the possibility of "extemporising" a quick survey in emergency conditions at very short notice.

For a very quick survey to succeed, however, a correct image acquisition method must be followed meticulously. The following are the key points to keep in mind setting up a data acquisition campaign:

1. Choosing the most suitable acquisition procedure for the boundary conditions in site and for the available lenses. This means trying to contain the perspective distortions as much as possible, using preferably only one lens and assuring an overlapping not less than $85 \%$. Where possible, shots at different heights must be taken, otherwise making shots at increasing distances from the building could be a good strategy.

2. Taking the photos in as short a time as possible, to avoid strong lighting changes.

3. Once the emergency phase has ceased, acquiring the position of no less than six control points with traditional topographic methods, using remarkable points of the building, in order to improve the quality of the photogrammetric modelling.

4. Shot with fix focal at highest resolution and image quality.

With a sufficient number of trained operators, the low-cost of photogrammetry would allow to carry out also large-scale surveys of cultural heritage. So, digital data archives useful both for catastrophic events and for cyclic state of maintenance monitoring could be made available.

The usefulness of photogrammetry techniques appears clearly in the discussed case study: a very quick photogrammetric survey conducted outside the building before the reinforcement system was put in place would have made it possible to record fundamental information for the stratigraphic analysis (Figure 8 ), whose importance does not concern only the historical, but also structural knowledge of the building.

\section{ACKNOWLEDGEMENTS}

The authors would like to acknowledge the Municipality of Mantua and Geogrà Srl for providing the lasers scanning datasets.

\section{REFERENCES}

3D Flow, 2018. 3DFlow 3DF Zephyr. Manuale utente versione 4.0. 3D Flow, Udine.

Agisoft, 2019. Agisoft Metashape User Manual: Professional Edition, Version 1.5. Agisoft, St. Petersburg.

Alidoost, F. and Arefi, H., 2017. Comparison of UAS-based photogrammetry software for $3 \mathrm{D}$ point clouds generation: a survey over a historical site. Int. Arch. Photogramm. Remote Sens. Spatial Inf. Sci., IV-4/W4, pp. 55-61.

https://doi.org/10.5194/isprs-annals-IV-4-W4-55-2017

Arcoraci, L., Berardi, M., Bernardini, F., Brizuela, B., Caracciolo, C.H., Castellano, C., Castelli, V., Cavaliere, A., Del Mese, S., Ercolani, E. et al., 2012. Rapporto macrosismico sui terremoti del 20 (ML 5.9) e del 29 maggio 2012 (ML 5.8 e 5.3) nella pianura padano-emiliana. Istituto Nazionale di Geofisica e Vulcanalogia, Italia.

http://www.questingv.it/index.php/rilievi-macrosismici/23pianura-padana-emiliana-20-05-2012-ml-5-9/file 
Carboni, N., Bruseker, G., Guillem, A., Bellido Castañeda, D., Coughenour, C., Domajnko, M., de Kramer, M., Ramos Calles, M. M., Stathopoulou, E. K. and Suma, R., 2016. Data provenance in photogrammetry through documentation protocols. ISPRS Ann. Photogramm. Remote Sens. Spatial Inf. Sci., III-5, pp. 57-64.

https://doi.org/10.5194/isprs-annals-III-5-57-2016, 2016

Di Tondo, S. and Fabrizi, E., 2013. Comparing photo modeling methodologies and techniques: the instance of the Great Temple of Abu Simbel. DISEGNARECON, 6 (12).

https://doi.org/10.6092/issn.1828-5961/3882

Fallavolita, F., Ballabeni, M., Foschi, R. and Perugini, G., 2015. Semantic description of three dimensional models of Bologna porches. SCIRES-IT, 5(1), pp. 31-40.

http://dx.doi.org/10.2423/i22394303v5n1p31

Fassi, F., Achille, C., Mandelli, A., Perfetti, L. and Polari, C., 2018. Recording the marble blocks of the Milan Cathedral: synergy between advanced survey techniques. Proceedings of the $10^{\text {th }}$ International Masonry Conference, Milan, Italy, July 2018, pp. 2124-2134.

Fassi, F. and Campanella, C., 2017. From daguerrotypes to digital automatic photogrammetry. Applications and limits for the built heritage project. Int. Arch. Photogramm. Remote Sens. Spatial Inf. Sci., XLII-5/W1, 313-319.

https://doi.org/10.5194/isprs-archives-XLII-5-W1-313-2017

Fassi, F., Rossi, C., and Mandelli, A., 2015. Emergency survey of remote and endangered archaeological sites. Int. Arch. Photogramm. Remote Sens. Spatial Inf. Sci., XL-5/W4, 85-91. https://doi.org/10.5194/isprsarchives-XL-5-W4-85-2015, 2015.

Fassi, F., Fregonese, L., Ackermann, S. and De Troia, V., 2013. Comparison between laser scanning and automated 3D modelling techniques to reconstruct complex and extensive cultural heritage areas. Int. Arch. Photogramm. Remote Sens. Spatial Inf. Sci., XL-5/W1, 73-80.

https://doi.org/10.5194/isprsarchives-XL-5-W1-73-2013

Gaglioloa, S., Ausonioa, E., Federicia, B., Ferrandoa, I., Passonia, D. and Sguerso, D., 2018. 3D Cultural Heritage documentation: a comparison between different photogrammetric software and their products. Int. Arch. Photogramm. Remote Sens. Spatial Inf. Sci., XLII-2, 347-354. https://doi.org/10.5194/isprs-archives-XLII-2-347-2018

Galli, P., Castenetto, S. and Peronace, E., 2012. Terremoti dell'Emilia - Maggio 2012. Rilievo macrosismico MCS speditivo. Rapporto finale 15 Giugno 2012, Dipartimento della Protezione Civile Nazionale, Roma, Italia.

http://www.protezionecivile.gov.it/resources/cms/documents/Te rremotoEmiliaMCS.pdf

Historic England, 2017. Photogrammetric Applications for Cultural Heritage. Guidance for Good Practice. Historic England, Swindon.

https://historicengland.org.uk/images-books/publications

Nikolov, I. and Madsen, C., 2016. Benchmarking Close-range Structure from Motion 3D Reconstruction Software Under Varying Capturing Conditions. In: Ioannides M. et al. (eds), Digital Heritage. Progress in Cultural Heritage:
Documentation, Preservation, and Protection. EuroMed 2016. Lecture Notes in Computer Science (10058). Springer, Cham. https://doi.org/10.1007/978-3-319-48496-9_2

Nocerino, E., Menna, F., and Remondino, F., 2014. Accuracy of typical photogrammetric networks in cultural heritage 3D modeling projects. Int. Arch. Photogramm. Remote Sens. Spatial Inf. Sci., XL-5, pp. 465-472.

https://doi.org/10.5194/isprsarchives-XL-5-465-2014

Perfetti, L., Fassi, F., and Gulsan, H., 2019. Generation of gigapixel orthophoto for the mainteinance of complex buildings. Challenges and lesson learnt. Int. Arch. Photogramm. Remote Sens. Spatial Inf. Sci., XLII-2/W9, pp. 605-614. https://doi.org/10.5194/isprs-archives-XLII-2-W9-605-2019

Valença, J., 2014. Systems based on photogrammetry to evaluation of built heritage: tentative guidelines and control parameters. Int. Arch. Photogramm. Remote Sens. Spatial Inf. Sci., XL-5, pp. 607-613.

https://doi.org/10.5194/isprsarchives-XL-5-607-2014 